\title{
Congenital anomalies in fetus during pregnancy-predisposing factor and management in rural set up
}

\author{
Sunil Somnath Patil ${ }^{1 *}$, Punam Bhimsing Pardeshi², Pradip Wamnrao Sambarey ${ }^{1}$
}

\begin{abstract}
${ }^{1}$ Department of Obstetrics and Gynecology, B. J. Govt. Medical College and Sassoon Hospital, Pune, Maharashtra, India

${ }^{2}$ Department of Obstetrics and Gynecology, S.R.T.R. Govt. Medical College and Hospital, Ambajogai, Maharashtra, India
\end{abstract}

Received: 19 May 2018

Accepted: 26 June 2018

\section{*Correspondence:}

Dr. Sunil Somnath Patil,

E-mail: sunilpatil0332@gmail.com

Copyright: (c) the author(s), publisher and licensee Medip Academy. This is an open-access article distributed under the terms of the Creative Commons Attribution Non-Commercial License, which permits unrestricted non-commercial use, distribution, and reproduction in any medium, provided the original work is properly cited.

\section{ABSTRACT}

Background: Congenital anomalies are the vital causes for perinatal mortality and morbidity. Therefore, an antenatal diagnosis and foetal therapy have attained importance in the field of human embryology.

Methods: This was an observational study conducted in antenatal, labour and postnatal ward at Rural medical college and hospital for 2 years. The aim of study is to review the overall frequency of congenital malformation and to increase public awareness in saving newborns from birth defects.

Results: Cause of congenital anomalies was unknown in $82.1 \%$ of the cases in our study. Out of 162 congenital anomalies $60.49 \%$ were antenataly registered whereas $39.51 \%$ were unregistered. Most common system involved in congenital anomaly was Central nervous system (CNS) followed by gastrointestinal anomaly. In central nervous system anencephaly was commonest abnormality. sensitivity of ultrasonography was $74.03 \%$ and specificity was $98.86 \%$.

Conclusions: Every mother should undergo early anomaly. Fortification of food with iron, folic acid, iodine should be carried out. Anemia should be tackled early in reproductive age group. Maternal perinatal infection can be prevented through vaccination and if identified, diagnosed and treated early, would also help in decreasing congenital anomalies in baby.

Keywords: Congenital anomaly, Antenatal diagnosis

\section{INTRODUCTION}

Human evolution from a single cell, 'zygote' to a multi cellular organism, is an intricate and a complex process. The birth of a malformed baby is an unfortunate event for any family and equally for the society too. Influence of teratogens in the form of pathogens, chemicals, environmental pollution and use of drugs by the mothers indiscriminately in their day to day life, have resulted in an increased incidence of congenital abnormalities in the newly born children. ${ }^{1}$ Congenital anomalies are the vital causes for perinatal mortality and morbidity. Therefore, an antenatal diagnosis and foetal therapy have attained importance in the field of human embryology. According to Dolk, "Environmental factors include any non genetic factor that increases the risk of a birth defect for the exposed individual. ${ }^{2}$

Such factors are nutritional excesses or deficiencies (e.g. folic acid), maternal illnesses or infections, drugs which are taken during pregnancy, chemical exposure in the workplace or home and radiation." Scientific literature is 
interested in the association between congenital anomalies and the possible role of chemical contaminants, and foetuses are thought to be a further subgroup of the population who could be vulnerable to the effects of air pollutants. 1,3 Many structural abnormalities in the fetus can be reliably diagnosed by an ultrasound scan, and these can usually be made before 20 weeks. Common examples include hydrocephalus, anencephaly, myelomeningocoele, achondroplasia and other dwarfism, spina bifida, exomphalos, Gastroschisis, duodenal atresia and fetal hydrops.

With more recent equipment, conditions such as cleft lips/ palate and congenital cardiac abnormalities are more readily diagnosed and at an earlier gestational age. The third one, could be done after the $26^{\text {th }}$ week of pregnancy. An ultrasound examination will not, of course detect chromosomal anomalies, inherited disorders of metabolism or gene defects such as sickle cell disease.

Some congenital abnormalities can be curable if they are detected early in the antenatal period (e.g. Cardiac anomalies). In - utero surgical interventions have been made possible by the advancement in the field of medicine. Pregnant women who carry anomalous foetuses can be counseled regarding the foetal anomalies and they can be sent to neonatal paediatricians for an early management or they can be advised to go for termination of pregnancy if the anomalies are of an incurable variety (e.g. anencephaly).

In view of the above, authors were prompt ted to take up the present study of congenital Anomalies in fetus during pregnancy" which involve all pregnant patient coming to Rural medical college and hospital. Apart from determining the incidence of congenital foetal abnormalities, such a study might bring to light certain factors which could possibly play an aetiological role in the production of foetal anomalies.

The aim of study is to review the overall frequency of congenital malformation and to increase public awareness in saving newborns from birth defects.

\section{To study}

1) Frequency of congenital anomalies

2) Most common congenital anomaly

3) Etiology of congenital malformation

4) Management of pregnancy and their follow up

\section{METHODS}

The present study was undertaken in a large multidisciplinary referral institute Rural medical college and hospital attached to a medical college. This was observational study and duration of the study was 2 years. The total number of confinements in 2 years were recorded.

\section{Inclusion criteria}

- All mothers who are diagnosed antenatally on ultrasonography with birth defect and delivered at Rural medical college and hospital

- All mothers who delivered babies with congenital birth defects at Rural medical college and hospital

- Babies admitted in postnatal ward with congenital birth defects

- Abortus showing congenital anomalies.

The following details were noted.

\section{Maternal details}

Every patient was evaluated closely and in detail. Age of the mother, consanguinity, past obstetric history, history of medical illness specifically viral infections in the form of rash/ fever in first trimester was noted. Details of intake of any drug intake, radiation exposure, family history was specifically noted. Her nutritional status, pallor was noted. Antenatal papers were screened for blood sugars level, blood pressure in antenatal period. Special note of ultrasonography findings for congenital anomalies, oligohydramnios, polyhydramnios was made in every patient. Associated medical and surgical illness was noted.

\section{Perinatal information}

Assessment as to whether pregnancy was terminated or continued after diagnosis of congenital anomaly was made. Mode of delivery, fetal outcome and management required postdelivery was noted. Foetal outcome in terms of weight, sex and type of congenital anomalies were noted.

Foetuses were followed, and note was made about their survival.

\section{RESULTS}

A total of 162 cases of various congenital anomalies were studied from November 2013 to May 2015.

Table 1: Total number of confinements with congenital anomalies detected / missed on USG.

\begin{tabular}{|ll|}
\hline Total confinements & 16170 \\
\hline Total live birth & 14814 \\
\hline Total abortions and ectopic pregnancies & 980 \\
\hline Total still births & 376 \\
\hline Total number of congenital anomalies detected & 162 \\
\hline $\begin{array}{l}\text { Total number of congenital anomalies detected } \\
\text { on USG }\end{array}$ & 114 \\
\hline Total anomalies missed on USG & 40 \\
\hline $\begin{array}{l}\text { Total number cases with congenital anomalies } \\
\text { in which USG was not done }\end{array}$ & 08 \\
\hline
\end{tabular}


Table 2: Distribution of cases.

\begin{tabular}{|lll|}
\hline \multicolumn{1}{|l}{ Frequency } & Percent \\
\hline Consanguinity & & \\
\hline Consanguineous & 19 & 11.73 \\
\hline Non-consanguineous & 143 & 88.27 \\
\hline Age of mother & & \\
\hline$\leq 20$ years & 4 & 2.47 \\
\hline 20-30 years & 148 & 91.36 \\
\hline$>30$ years & 10 & 6.17 \\
\hline Parity & & \\
\hline Primi & 68 & 41.98 \\
\hline Multi & 94 & 58.02 \\
\hline Antenatal registration & \\
\hline Registered & 98 & 60.49 \\
\hline Unregistered & 64 & 39.51 \\
\hline Sex of fetus & & \\
\hline Female & 88 & 54.32 \\
\hline Male & 74 & 45.68 \\
\hline Gestational age & & \\
\hline$<20$ weeks & 81 & 50.0 \\
\hline 20-27.6 weeks & 15 & 9.26 \\
\hline 28-36.6 weeks & 26 & 16.05 \\
\hline$\geq 37$ weeks & 40 & 24.69 \\
\hline Outcome & & \\
\hline Live & 62 & 38.27 \\
\hline Still birth & 19 & 50.0 \\
\hline Abortion & 81 & \\
\hline
\end{tabular}

Total number of confinements during period 2 years were 16170. Of which 14814 were live birth, 980 were abortions and ectopic pregnancies and 376 were still birth. Of the above confinements a total number of pregnancies with congenital anomalies were 162, detected either prenatally or after birth i.e. an incidence of 10.94/1000 Live Birth. Out of 162 anomalies, 114 congenital anomalies were prenatally diagnosed, whereas 40 anomalies were missed on ultrasonography. 8 cases did not have antenatal USG. Out of the 16170 confinements 9860 mothers had done antenatal USG scan.

Table 3: Distribution of study group as per maternal high-risk factor.

\begin{tabular}{|ll|}
\hline Congenital anomaly & Frequency \\
\hline Elderly mother & 11 \\
\hline Hydrocephalus & 3 \\
\hline Duodenal atresia & 3 \\
\hline CTEV & 3 \\
\hline Cleft lip and palate & \\
\hline Family history & 6 \\
\hline Achondroplasia & 8 \\
\hline Hydrocephalus & 1 \\
\hline Skeletal dysplasia & 2 \\
\hline Scoliosis & \\
\hline Severe anemia & 3 \\
\hline Anencephaly & 2 \\
\hline Hydrocephalus & 1 \\
\hline CTEV & 1 \\
\hline Hydrops fetalis & 1 \\
\hline Hirschprungs disease & \\
\hline Chronic malnutrition & 6 \\
\hline Neural tube defect & 2 \\
\hline Cleft lip and palate & 1 \\
\hline Hydrops fetalis & \\
\hline
\end{tabular}

Table 4: Distribution of congenital anomaly as per system involved.

\begin{tabular}{|c|c|c|c|c|c|c|c|}
\hline Anomaly found & $\begin{array}{l}\text { Diagnosed } \\
\text { on USG }\end{array}$ & $\begin{array}{l}\text { Missed } \\
\text { on USG }\end{array}$ & Total & Anomaly found & $\begin{array}{l}\text { Diagnosed } \\
\text { on USG }\end{array}$ & $\begin{array}{l}\text { Missed } \\
\text { on USG }\end{array}$ & Total \\
\hline Central Nervous system & & & & Gastrointestinal system & & & \\
\hline Anencephaly & 25 & 0 & 25 & Imperforate anus & 0 & 4 & 4 \\
\hline Hydrocephalus & 18 & 1 & 19 & Ileal atresia & 4 & 2 & 6 \\
\hline Neural tube defect & 6 & 1 & 7 & Congenital pyloric stenosis & 3 & 2 & 5 \\
\hline Choroid plexus cyst & 5 & 0 & 5 & Hirschprungs disease & 4 & 0 & 4 \\
\hline Corpus callosal agenesis & 1 & 3 & 4 & Intestinal obstruction & 3 & 0 & 3 \\
\hline Arnold Chiary malformation & 2 & 0 & 2 & Omphalocele & 6 & 0 & 6 \\
\hline Holoprosencephaly & 3 & 0 & 3 & Gastroschisis & 6 & 0 & 6 \\
\hline $\begin{array}{l}\text { NTD with Arnold Chiary } \\
\text { malformation }\end{array}$ & 1 & 0 & 1 & Duodenal atresia & 2 & 0 & 2 \\
\hline Total & 61 & 5 & 66 & Midgut malrotation & 1 & 1 & 2 \\
\hline Skeletal system & & & & Esophageal atresia & 1 & 0 & 1 \\
\hline Cleft lip and cleft palate & 1 & 16 & 17 & Total & 30 & 9 & 39 \\
\hline Congenital dislocation of Hip & 7 & 0 & 7 & Renal system & & & \\
\hline CTEV & 5 & 0 & 5 & $\begin{array}{l}\text { Dilatation of pelvicalyceal } \\
\text { system }\end{array}$ & 7 & 0 & 7 \\
\hline Achondroplasia & 4 & 0 & 4 & Renal cyst & 4 & 0 & 4 \\
\hline Calcaneovalgus deformity & 2 & 0 & 2 & Single kidney & 4 & 0 & 4 \\
\hline Congenital vertical Talus & 0 & 1 & 1 & PUJ obstruction & 6 & 0 & 6 \\
\hline Others & 3 & 7 & 10 & Total & 21 & 0 & 21 \\
\hline Total & 22 & 24 & 46 & & & & \\
\hline
\end{tabular}


Table 5: Postnatal Management required.

\begin{tabular}{|lll|}
\hline $\begin{array}{l}\text { Postmatal management } \\
\text { required }\end{array}$ & Frequency & Percentage \\
\hline Active management & 21 & 12.96 \\
\hline $\begin{array}{l}\text { Conservative } \\
\text { management }\end{array}$ & 40 & 24.69 \\
\hline No active management & 10 & 6.17 \\
\hline No management (dead) & 91 & 56.17 \\
\hline Total & 162 & 100 \\
\hline
\end{tabular}

Out of 162 congenital anomalies, 21 anomalies required active management in the form of surgery or medical management. 40 cases were managed conservatively 10 cases were observed and followed up subsequently, did not require active management.

\section{DISCUSSION}

Preeclampsia leads to increased perinatal morbidity and Birth defects include abnormalities in the new born baby's structure, function or body metabolism which usually lead to physical and mental disabilities and can even be fatal sometimes. Congenital anomalies are important causes of still births and infant mortality, and are contributors to childhood morbidity.

Congenital anomalies account for $8-15 \%$ of perinatal deaths and $13-16 \%$ of neonatal deaths in India. ${ }^{4}$

In India, birth defect prevalence varies from 61-69/1000 live birth which is higher as compared to developed countries. 5

In study conducted by Sarkar et al prevalence of congenital anomaly was $22.16 / 1000$ live births. ${ }^{6}$ In study conducted by Amar Taksande incidence of congenital anomaly was 19.1/1000 live births. In present study 162 congenital anomalies were reported in span of 2 years. Incidence rate of congenital anomaly was 10.94/ 1000 live births. Antenatally diagnosed cases were 114 $(74.03 \%)$

Consanguinity was observed in 19 cases $(11.73 \%)$ of the total 162 (Table 2)

Consanguineous marriages being more common in Indian culture, increases the risk of congenital malformation. Hence premarital counseling is required.

Majority of mothers of babies with congenital anomaly belonged to age group 20-30 years (91.33\%) (Table 2). In a study conducted by Sarkar et al $55.7 \%$ belonged to age group of 21-30 years. ${ }^{6}$

Majority of cases were observed in multiparous mothers $(57.9 \%)$, as compared to Primipara $(42.1 \%)$ (Table 2$)$. In a study conducted by Taksande et $\mathrm{al}^{7}$ Incidence of congenital anomalies was found to be more common in multipara, Sarkar et al also found the incidence of congenital anomalies more common in multipara as compared to primipara. ${ }^{6}$ Multiparous mothers should be screened vigilantly with antenatal detailed congenital anomaly scan, as more number of congenital anomaly are found in multiparous woman.

Out of 162 congenital anomalies $60.49 \%$ were antenataly registered whereas $39.51 \%$ were unregistered, (Table 2). Since most of the woman seek antenatal care, more congenital anomalies were observed in registered pregnancies. Patient who are antenatally registered in mid second trimester diagnostic modality like ultrasonography may be delayed. Awareness about antenatal registration needs to be stressed for proper antenatal care and proper development of foetus, and to identify congenital anomalies at the earliest. Delivery at tertiary care center is advisable as some of the congenital abnormality require immediate medical or surgical management. Congenital anomalies were found to be more common in females than males (Table 2). Most of the babies with congenital anomalies were delivered at full term, 06 were delivered by caesarean section. Most of them were hydrocephalus having cephalo-pelvic disproportion.81 cases were terminated before 20th week of gestation for life threatening congenital anomaly, (Table 2). 25 of them had anencephaly, (Table 4).

Sarkar et al had observed more number of cases in babies born prematurely. ${ }^{6}$

Most of the babies with congenital anomalies had normal birth weight. This observation is in contrast to the result obtained by Sarkar et al. ${ }^{6}$ Present study result correlates well with the finding made by Amar taksande7 et al.38.27\% of the cases with congenital anomaly had live birth, (Table 2). ${ }^{7}$ Taksande et al had also observed $94.2 \%$ babies of congenital anomalies being live at birth. ${ }^{7}$

Most commonly implicated high-risk factor was increased maternal age. Mothers aged 30 years and above were 10 in number. Sugunabai et al reported a higher incidence of malformations in the babies born to mothers aged over 35 years, whereas Datta et al documented statistically insignificant association of increased maternal age and congenital anomalies. ${ }^{8,9}$ Family history was found to be significant high-risk factor in 6 cases of short stature. Carrier frequencies for various genetic disorders like thalassemia, sickle cell anemia, and metabolic disorder are high among Indians. Severe anemia and chronic malnutrition were found to be significant high-risk factor in neural tube defects, (Table 3). Maternal deficiencies of iodine and folic acid and other macro and micro nutrient found to be associated with birth defects. Sensitivity of ultrasonography in diagnosis of congenital abnormality was $74.03 \%$.

Most common system involved in congenital anomaly was Central nervous system (CNS) followed by gastrointestinal anomaly. In study conducted by Indian 
council of medical research (ICMR) most common anomaly was cardiovascular anomalies followed by musculoskeletal system (Table 4). ${ }^{10}$ Neural tube defects was the commonest anomaly found in our study, (Table 4) implying need for improving nutritional status of woman in reproductive age group and increased use of periconceptional use of folate. In central nervous system anencephaly was commonest abnormality, all of them were diagnosed prenatally by USG. Other anomalies like Arnold chiary malformation, hydrocephalus were also diagnosed prenatally on USG, (Table 4). Cleft lip and palate were the commonest skeletal abnormality followed by congenital dislocation of hip and CTEV, (Table 4).

Epispadiasis was commonest abnormality in genitourinary system, followed by cryptorchidism. None of them were picked up on USG, (table no 4). Dilatation of pelvicalyceal system was commonest renal anomaly, all of them were diagnosed on USG. Imperforate anus and ileal atresia were commonest gastro-intestinal anomaly, required operative intervention.

Congenital diaphragmatic hernia and choanal atresia was commonest respiratory anomaly.

\section{CONCLUSION}

This observational study was carried out in a rural medical college over a period of 23 months.

As cause of congenital anomalies was unknown in $82.1 \%$ of the cases in our study, every mother should undergo early anomaly scan (early second trimester) and delivery at tertiary care centre is advisable as some of the congenital anomalies require immediate surgical or medical management.

Although $60.49 \%$ were antenatally registered most of them were registered after $20^{\text {th }}$ week i.e. after legal gestational age of termination of pregnancy. Hence early registration as soon as pregnancy is confirmed should be encouraged so as to make an early diagnosis and selection of plan of management. Thereby reducing fetal morbidity and improving neonatal survival.

In the present study, sensitivity of ultrasonography was $74.03 \%$ and specificity was $98.86 \%$, as per Table 2 . Ideally basic ultrasound examination should be done in all the patients. More detailed ultrasonographic study (Targeted USG) should be done in high risk group .

Fetal echocardiography is directed towards selected pregnancies carrying a higher than normal risk of fetal cardiac anomalies

Consanguinous marriages are still common in Indian culture, as per Table 3, increasing the risk for congenital malformations. Proper premarital counselling and carrier detection for common inherited disorders. The knowledge and awareness regarding the availability of various other diagnostic modalities including serum markers, amniocentesis, chorion villus sampling, cordocentesis should be given to the patient. Most of the congenital anomalies are preventable by proper premarital counselling, periconceptional care in the form of improving maternal nutrition, folic acid supplementation, avoidance of teratogenic agents. Most of the anomalies can be picked up by fetal anomaly scan early mid trimester and life-threatening anomalies can be terminated. Attempts to prevent congenital anomalies should be initiated in preconceptional period and continued through the antenatal period upto birth of baby. High risk patients should be counselled and prepared in pre and periconceptional period.

Maternal anemia and malnutrition pose a serious threat to both mother and fetus, hence fortification of food with iron, folic acid, iodine should be carried out. Anemia should be tackled early in reproductive age group.

Maternal perinatal infection can be prevented through vaccination and if identified, diagnosed and treated early, would also help in decreasing congenital anomalies in baby.

\section{Funding: No funding sources Conflict of interest: None declared \\ Ethical approval: The study was approved by the Institutional Ethics Committee}

\section{REFERENCES}

1. Dolk H. Epidemiologic approaches to identifying environmental causes of birth defects. Am J Med Genetics Part C: Seminars in Medical Genetics 2004;125(1):4-11. Hoboken: Wiley Subscription Services, Inc., A Wiley Company.

2. Dolk H. In special report: A Review of Environmental Risk Factors for Congenital Anomalies. Co Antrim Northern Ireland: University of Ulster Newtownabbey. Epidemiological evidence regarding environmental causes of congenital anomalies: interpretational issues. 2004;30-47.

3. Pope 3rd CA. Epidemiology of fine particulate air pollution and human health: biologic mechanisms and who's at risk?. Enviro Health Perspectives. 2000;108(Suppl 4):713.

4. Medindia. Birth Defects Registry of India - A 'Saving Babies' Project. Available at http://www.medindia.net/news/healthwatch/BirthDefects-Registry-of-India- A-Saving-Babies-Project78389-1.htm\#ixzz2GtO6Ld5M.

5. World health organization. Management of birth defects and haemoglobin disorders: Report of a Joint WHO-March of Dimes meeting. Geneva, Switzerland, Geneva: WHO.2006.

6. Sarkar S, Patra C, Dasgupta MK, Nayek K, Karmakar PR. Prevalence of congenital anomalies in neonates and associated risk factors in a tertiary care 
hospital in eastern India. J Clin Neonatol. 2013;2(3):131-4.

7. Taksande A, Vilhekar K, Chaturvedi P, Jain M. Congenital malformations at birth in Central India: A rural medical college hospital based data. Indian J Hum Genetics. 2010;16(3):159.

8. Suguna NB, Mascarene M, Syamalan K, Nair PM. An etiological study of congenital malformation in the newborn. Indian Pediatr. 1982;19(12):1003-7.

9. Vikram D, Pushpa C. Congenital malformations in rural Maharashtra. Indian Pediatr. 2000;37(9):9981001 .
10. Reproductive health; Annual report 2002-03. Indian Council of Medical Research. 91. Available at http://planningcommission.gov.in/reports/genrep/are p0203/ar0203eng.pdf

Cite this article as: Patil SS, Pardeshi PB, Sambarey PW. Congenital anomalies in fetus during pregnancy -predisposing factor and management in rural set up. Int J Reprod Contracept Obstet Gynecol 2018;7:3173-8 